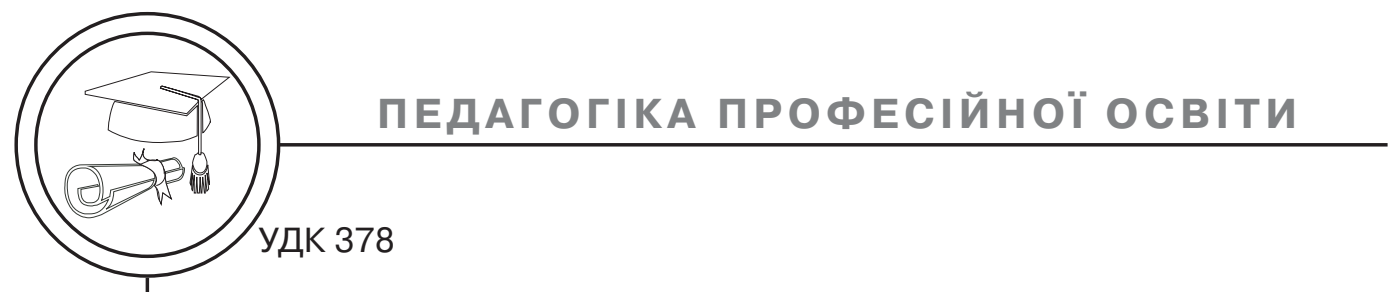

( А. В. Бізюк, канд. техн. наук, доц., В. П. Ткаченко, канд. техн. наук, проф., ХНУРЕ, В. В. Бізюк, канд. техн. наук, доц., ХНУМГ ім. О. І. Бекетова, Харків, Україна

\title{
ДОСЛІДЖЕННЯ СТРУКТУРНО-ЛОГІЧНОЇ СХЕМИ НАВЧАННЯ МЕТОДАМИ ТЕОРІї ГРАФІВ
}

\begin{abstract}
У статті на підставі аналізу робіт на тему складання навчальних планів запропоновано застосування методики вивчення кореляційних процесів у структурі навчання засобами теорії графів. Дослідження базується на припущенні щодо кореляції відносного обсягу викладання дисципліни в навчальному плані та її затребуваності
\end{abstract} у формуванні професійних компетентностей випускника. Впровадження результатів дослідження дозволить збільшити об'єктивність засобів математичного моделювання й інформаційної підтримки в задачах оптимізації навчальних планів, розподілу циклів дисциплін навчальних планів за семестрами.

Ключові слова: Навчальний план; теорія графів; структура навчання; дисципліна; кредит; компетенція; інформаційні технології.

\section{Вступ}

Завдання вдосконалення методик розробки навчальних планів, що використовують сучасні інформаційні програмні засоби та технології, нагальне для вітчизняної освіти. Прийнятий курс на збільшення автономії закладів вищої освіти (ЗВО) та зміну нормативних обмежень із переліку обов'язкових дисциплін до переліку необхідних компетентностей, збільшує варіативність навчальних планів і, відповідно, обсяг робіт щодо їх формування, а зниження трудомісткості цієї роботи можливе тільки завдяки застосуванню відповідних засобів автоматизації і формального аналізу.

\section{Постановка проблеми}

Процес розробки й аналізу навчальних планів нині потребує вдосконалення, наукового обґрунтування й інформаційної підтримки прийняття рішень. Незважаючи на велику різноманітність можливих підходів, більшість з них заснована на досвіді й інтуїції працівників вищої школи. Для формування навчальних планів групі розробників потрібний, як правило, не один рік педагогічної роботи. Тому спроби моделювання навчального процесу допомагають застосувати можливості технічних засобів обробки інформації та врахувати рекомендації щодо взаємодоповнення технологічних

(C) $2019 \mathrm{p}$. 
і організаційних рішень, розроблених, наприклад, у складі стандартів.

\section{Аналіз попередніх досліджень}

Авторами був проведений аналіз робіт, в яких тим чи іншим чином розглянуто застосування математичних моделей, зокрема методів теорії графів, у задачах оптимізації навчальних планів. 3 урахуванням значної кількості формальних обмежень предметної області сутність більшості робіт складає задача розподілу дисциплін за семестрами із обмеженням сумарної кількості кредитів на семестр. Здебільшого, перелік дисциплін є фіксованим. Проте, у деяких розробках підставою для включення дисципліни до навчального плану визначалась важливість дисципліни з певних умов. Завдання автоматизованого синтезу або оптимізації навчального плану вирішувалось на основі алгоритмів теорії графів або матричних обчислень, однак задача, що має за основу граф зв'язаності навчальних дисциплін і розподіл вагомості різних циклів дисциплін плану, раніше не ставилася.

Отже, дослідження, пов'язані з вдосконаленням і розробкою інформаційних систем аналізу та синтезу навчальних планів у системі вищої освіти, які можуть усунути вказані недоліки, є актуальними.

\section{Мета роботи}

3 огляду на попередні висновки, була сформульована мета дослідження: розробка методики математичного моделювання нав- чальних планів вищої технічної освіти, проведення обчислювальних експериментів задля аналізу й оптимізації навчальних планів. Зокрема, було досліджено методику визначення значущості дисциплін навчального плану на підставі статистичного аналізу розподілу тем дипломного проектування за типовими тематиками.

\section{Результати проведених досліджень}

Об'єктом дослідження є навчальний план програми підготовки бакалаврів (на прикладі навчального плану спеціальності 186 Видавництво та поліграфія ХНУРЕ) як перелік дисциплін, пов'язаних між собою певними структурно-логічними зв'язками. Предмет дослідження - процес формування й удосконалення навчальних планів технічних спеціальностей.

Запропонована в ході дослідження методика може бути використана при розробці та практичній реалізації інформаційних систем управління навчальним процесом 3ВО.

У ряді наукових робіт [1-6] розглянуто різні варіанти автоматизованого синтезу навчального плану. У простих випадках вирішено завдання розподілу навчальних дисциплін за семестрами з урахуванням обмежень, що задані стандартом. У складних системах враховано логічні ланцюжки послідовно навчальних дисциплін із урахуванням їхнього взаємозв'язку.

Наразі автоматизоване формування навчального плану зустрічається рідко [6], про що свідчить велика кількість методичних 
матеріалів, представлених на сайтах ЗВО, які містять рекомендації саме щодо ручного формування навчального плану.

1. Запропоновано формалізовані математичні постановки завдання оптимізації розподілу дисциплін за роками та семестрами з урахуванням відповідних обмежень: виду дисциплін (загальноосвітні, профілюючі), кількості тижнів у семестрі, годин на тиждень, зв'язності дисциплін, розподілу тривалих дисциплін на модулі і тому подібне $[2,7]$. Цей підхід продовжує розвиватися [1, 8 та ін.]. Значущість дисциплін, тобто необхідність додавання дисципліни до навчального плану, може визначатися, наприклад, обсягом викладання або кількістю компетентостей, які розкриває певна дисципліна [9].

Складність і розмірність таких завдань вимагає розробки спеціальних програмних продуктів, заснованих на ідеї динамічного програмування. Постановка завдання, визначення початкових даних і обмежень пов'язана з великими витратами часу, що непросто реалізувати в реальних умовах розробки планів. Крім того, початкові дані й обмеження для таких моделей задаються експертами-викладачами, і перевірити їх об'єктивність неможливо.

У цьому дослідженні навчальний план представлено у вигляді орієнтованого графа, в якому ребра позначають зв'язки між дисциплінами (пререквізити та постреквізити). Передбачено, що в плані немає зворотних зв'язків між вершинами, що могли б утворювати цикли. Такий підхід зустрічається, зокрема, в забезпеченні алгоритмів функціонування програмних продуктів для автоматизації роботи з навчальними планами [9-11].

Наприклад:

$$
\begin{aligned}
& \mathrm{D}=\left\{\mathrm{D}_{1}, \mathrm{D}_{2}, . ., \mathrm{D}_{\mathrm{i}}, . ., \mathrm{D}_{\mathrm{n}}\right\} \\
& \mathrm{U}=\left\{\mathrm{U}_{1,2}, \mathrm{U}_{2,3}, . ., \mathrm{U}_{\mathrm{i}, \mathrm{j}} . .\right\}
\end{aligned}
$$

де $D$ - множина вершин $D_{i}$, які відповідають переліку дисциплін навчального плану; U - множина орієнтованих дуг (зв'язків між вершинами), які відповідають структурно-логічним міждисциплінарним зв'язкам; $U_{i, j}=\left(D_{i}, D_{j}\right)-$ орієнтована дуга, що характеризує направлення передачі інформації з вершини $D_{i}$ у вершину $D_{j}$.

Тоді граф можна позначити символом $\mathrm{G}(\mathrm{D}, \mathrm{U})$.

Таким чином, мережевий графік навчального плану є графічним зображенням робіт (навчальних операцій), логічно сполучених між собою. Здебільшого, загальні мережеві математичні моделі ускладнюються ще жорсткішими вимогами: окрім спрямованості, в графі має бути тільки одне джерело (вершина, яка не має дуг, що входять) і один стік (вершина, яка не має дуг, що виходять). Накладаються також вимоги відсутності безвиході (проміжних вершин, що відгалужуються або не мають вихідних дуг).

Дослідження такої моделі методами теорії графів використано для вивчення структурно-логічної послідовності викладення дисциплін [2, 8], для оптимального розташування дисциплін за семестрами [1].

Для формування й аналізу такого графа застосовано різні моделі: аналіз зв'язності дисци- 
плін [6], розробка мови моделювання з граматикою типу «умовного наслідування» [12], статистичні моделі [6] тощо.

Питаннями «значущості» вершин орієнтованого графу навчального плану, тобто розрахунками важливості тієї чи іншої дисципліни в загальній програмі навчання студента, займалися автори Котов С. С., Столбов В. Ю. [5]. Їхній підхід спирався на евристичне (експертне) оцінювання значущості вершин графу.

Для отримання більш диференційованих оцінок дисциплін можна застосувати інформаційні оцінки міри впливу компонентів рівнів графу, що розташовані ієрархічно нижче, на компоненти вищого рівня. Такий підхід запропонований Денісовим А. А. [3]. В його роботі було розраховано оцінки важливості дисципліни $\mathrm{H}_{\mathrm{i}}$ у роботі кафедри:

$$
\mathrm{H}_{\mathrm{i}}=-\mathrm{q}_{\mathrm{i}} \lg (1-\mathrm{pi})
$$

де $\mathrm{p}_{\mathrm{i}}$ - міра впливу на досягнення вимог, 0,7 > $\mathrm{p}_{\mathrm{i}}>0,99 ; \mathrm{q}_{\mathrm{i}}-$ вірогідність реалізації того, що цю дисципліну можна забезпечити силами викладачів кафедри.
Отже, застосування елементів теорії графів у дослідженні процесів навчання, зокрема структури навчального плану, $є$ актуальним засобом математичного моделювання. У рамках дослідження здійснено аналіз навчального плану підготовки бакалаврів зі спеціальності 186 Видавництво та поліграфія ХНУРЕ як структурно-логічної послідовності елементів навчання, вираженого у вигляді графу (рис. 1).

Гіпотезою дослідження було припущення, що значимість окремих дисциплін, як елементів описаного графу, відповідає i може корелювати в частоті вибору студентами відповідних тем для дипломних робіт.

При цьому було припущено, що на значимість дисципліни (яка може бути виражена в умовних балах) впливає на:

- обсяг навчального навантаження, відведеного для вивчення дисципліни, що виражений у кредитах ECTS або в навчальних годинах:

- потреба у викладенні дисципліни для вивчення дисциплін

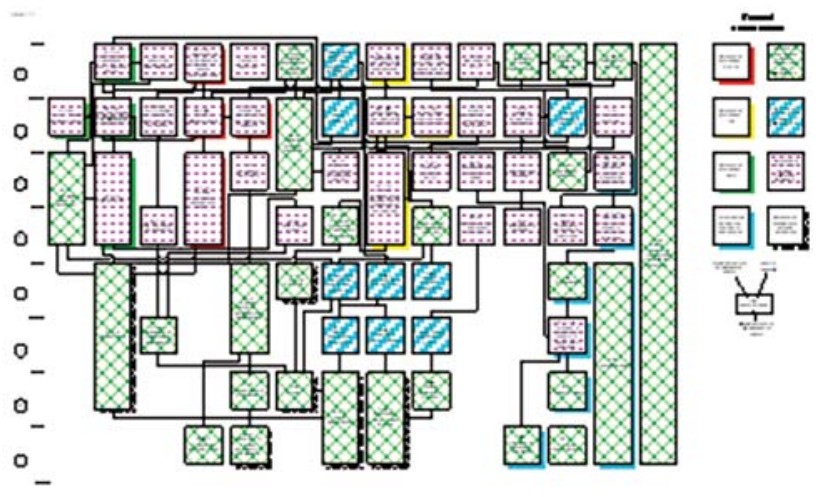

Рис. 1. Загальна структурно-логічна схема дисциплін навчального плану 
наступного, більш високого рівня в структурно-логічній послідовності.

Вплив кожної дисципліни на кінцеві вершини, тобто потреба у вивченні конкретної дисципліни навчального плану для успішного виконання дипломної роботи за певною тематикою, був врахований завдяки аналізу орієнтованого графу.

$$
\mathrm{W}_{\mathrm{i}}=\sum_{\mathrm{n}} \frac{1}{2^{\mathrm{n}}} \mathrm{U}_{\mathrm{ij}}^{\mathrm{n}}
$$

Тут через $U_{i, j} \mid(0 ; 1)$ позначена наявність орієнтованої дуги, що може бути відстежена до відповідної вершини $\mathrm{D}_{\mathrm{i}}$ Змінна $\mathrm{n}$ характеризує кількість ланцюжків на цьому шляху, тобто елементи рівня $\mathrm{n}=0$ безпосередньо передують цій дисципліні, елементи рівня $\mathrm{n}=1$ розташовані через одну і так далі.

Сумарна значимість впливу дисциплін навчального плану $\mathrm{M}_{\mathrm{i}}$ на кінцеві вершини, тобто умовний рейтинг тематики за вкладом вивченого матеріалу, розраховується як

$$
\mathrm{M}_{\mathrm{i}}=\sum_{\mathrm{j}} \mathrm{W}_{\mathrm{j}} \mathrm{K}_{\mathrm{j}}
$$

де $\mathrm{W}_{\mathrm{j}}$ - вплив дисциплін як елементів орієнтованого графа на кінцеві вершини; $\mathrm{K}_{\mathrm{j}}$ - обсяг дисципліни в кредитах ECTS

Такий підхід, для якого характерно визначення «значущості» або «важливості» дисципліни через її попередників був описаний, зокрема, в роботах Лайтфута Дж. М. [13].

Для кожної узагальненої тематики дипломного проектування було розраховано відносний рейтинг загальної значимості всіх дисциплін, які безпосередньо або опосередковано $€$ необхідними для успішного виконання атестаційної роботи як головного показника засвоєння компетентностей (рис. 2).

Так максимальні рейтингові бали отримали дисципліни загальної фундаментальної підготовки (Інформатика, Вища математика), які $€$ передумовою успішного вивчення багатьох інших дисци-

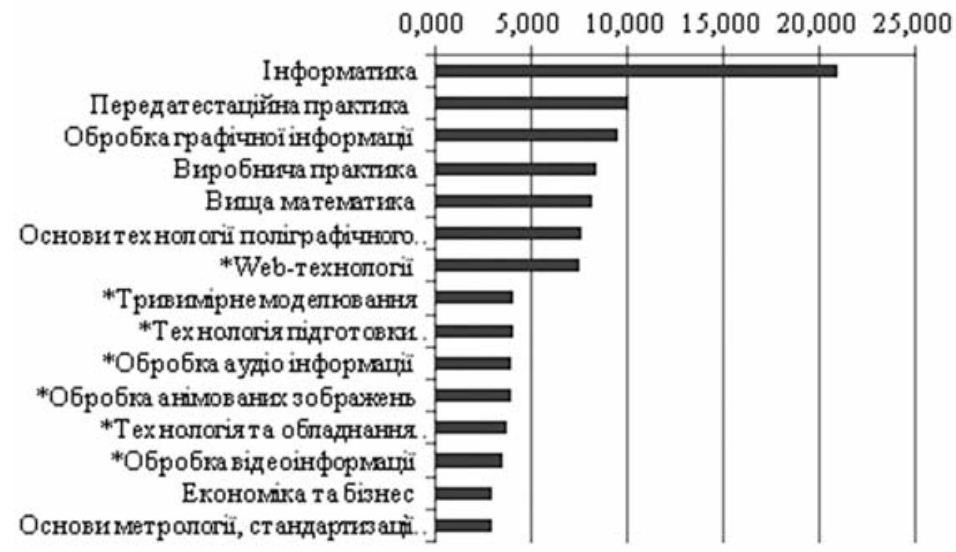

Рис. 2. Діаграма рейтингу дисциплін навчального плану 
плін; дисципліни загальної професійної підготовки (Основи технології поліграфічного виробництва, Web-технології, Технологія підготовки електронних видань); дисципліни, які стосуються підготовки контексту (Обробка графічної інформації, Обробка анімованих зображень, Обробка аудіоінформації), а також обидві практики (передатестаційна 4-го курсу та виробнича 3-го курсу) як необхідні для підготовки практичних розділів атестаційної роботи.

Серед дисциплін, що посіли останні за рейтингом місця - переважно дисципліни вільного вибору студента, які обираються лише частиною студентів і мають відносно невелике втілення в атестаційних роботах за відповідною тематикою.

Результати розрахунків зведені в таблицю.
Інший аспект дослідження був зосереджений на порівняльному аналізі відносної кількості тем атестаційних робіт і відносного розподілу навчальних ресурсів (тобто кредитів ECTS) у загальному обсязі запропонованих дисциплін (див. табл. та рис. 3). Такий підхід, за якого кінцева мета навчання, тобто перелік дисциплін, визначається формалізованою сукупністю категорійних елементів (у нашому випадку їй можна зіставити сукупність тем атестаційних робіт) був викладений у роботах Pasterk, Bollin [14, 15].

\section{Висновки}

Здійснений аналіз дозволяє проводити вдосконалення переліку дисциплін навчального плану на підставі кореляції кількісних покажчиків типових тем дипломного проектування й обсягів вивчення дисципліни. Передбачено, що

Відносний розподіл тем атестаційних робіт

\begin{tabular}{|c|c|c|c|}
\hline $\begin{array}{l}\text { № } \\
\Pi / 4\end{array}$ & Напрямок тематики дипломного проектування & $\begin{array}{l}\text { За креди- } \\
\text { тами, \% }\end{array}$ & $\begin{array}{l}\text { За тема- } \\
\text { ми, \% }\end{array}$ \\
\hline 1 & Проектування та розробка сайтів & 10 & 32 \\
\hline 2 & Проектування та розробка електронних видань & 12 & 20 \\
\hline 3 & Проектування та розробка мобільних додатків & 8 & 6 \\
\hline 4 & Проектування та розробка UI/UX та інтерфейсів & 8 & 3 \\
\hline 5 & Проектування та розробка відео-додатків & 8 & 3 \\
\hline 6 & $\begin{array}{l}\text { Розробка елементів з використанням 3D- } \\
\text { моделювання }\end{array}$ & 8 & 3 \\
\hline 7 & Розробка фірмового стилю акцидентної продукції & 8 & 11 \\
\hline 8 & $\begin{array}{l}\text { Проектування та розробка оригінал-макету дру- } \\
\text { кованого видання }\end{array}$ & 9 & 14 \\
\hline 9 & Проектування та розробка поліграфічних виробів & 8 & 3 \\
\hline 10 & $\begin{array}{l}\text { Автоматизація управління технологічними про- } \\
\text { цесами }\end{array}$ & 11 & 2 \\
\hline 11 & $\begin{array}{l}\text { Дослідження та провадження поліграфічних тех- } \\
\text { нологій }\end{array}$ & 12 & 5 \\
\hline
\end{tabular}




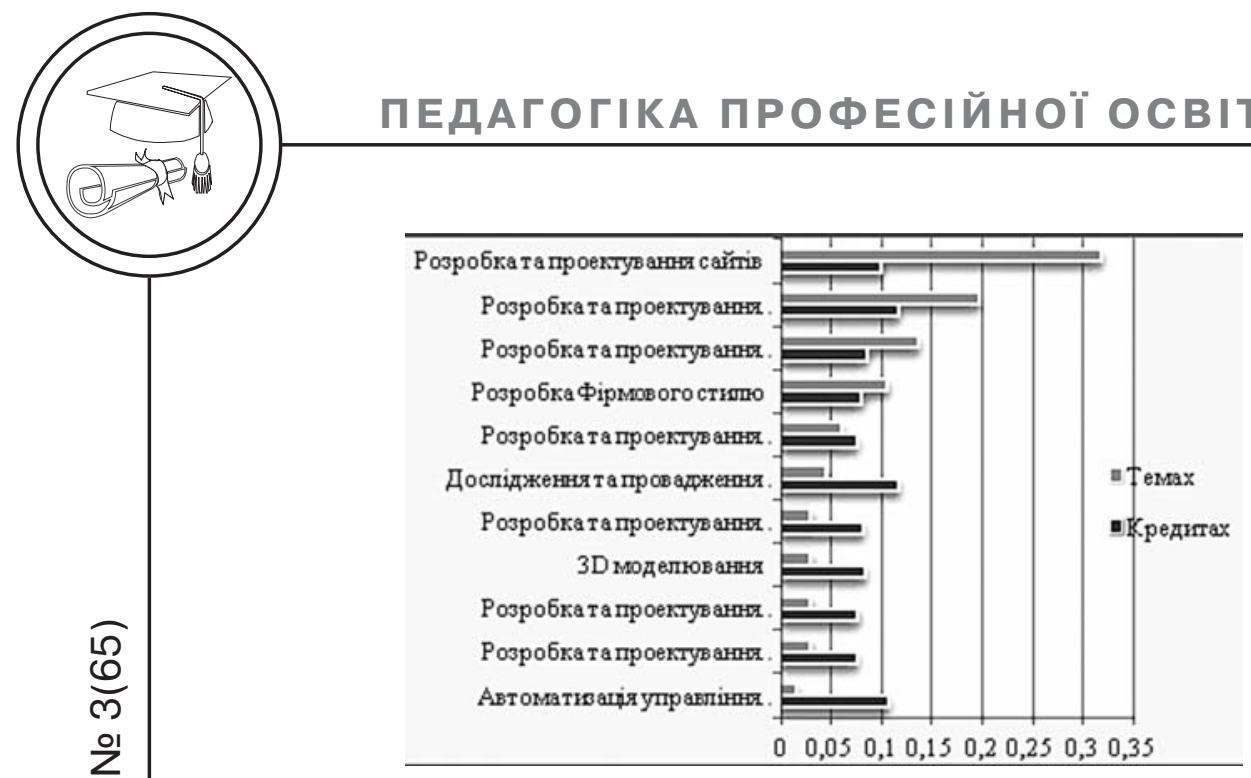

Рис. 3. Діаграма рейтингу тем атестаційних робіт

кількість дипломних робіт певної тематики пропорційна сумарному обсягу відповідних дисциплін. 3 іншого боку, зацікавленість студентів у дипломних дослідженнях певної тематики залежить від місця проходження практики та персональних вподобань студента щодо його подальшого працевлаштування. Тобто, з цієї точки зору вибір тематики корелює з побажаннями підприємств, що є базами практики, як замовників випускників кафедри на ринку праці.
Таким чином, порушення кореляції свідчить про невідповідність компонентів у зв'язку «Навчальні дисципліни»-«Зацікавленість стейкхолдерів». Можна рекомендувати провести оптимізацію навчального плану на підставі описаного аналізу шляхом скорочення менш значимих дисциплін і збільшення або додавання сучасних тем і розділів у наявні дисципліни з відповідними змінами обсягів навчання.

\section{Список використаної літератури}

1. Агаджанов Г. Г. Некоторые критерии оптимизации учебных планов / Г. Г. Агаджанов, В. С. Найденко, В. С. Тоискин // Научный электронный архив. URL: http://econf.rae.ru/article/7755.

2. Волкова В. Н. Модели и автоматизированные технологии для разработки учебных планов / В. Н. Волкова, А. А. Ефремов, А. В. Логинова, Д. А. Кабинетская, М. А. Тамбаум // Открытое образование. 2016. № 6. С. 51-58.

3. Денисов А. А. Современные проблемы системного анализа: учебник / А. А. Денисов. СПб.: Изд-во Политехнического университета, 2009. 304 с.

4. Ефремов А. A. System analysis of the development of workplans for the preparation of bachelors / А. А. Ефремов, Д. А. Кабинетская, М. А. Тамбаум // System analysis in design and management: Collection of Scientific Works XVIII Int. scientific and practical conf. Part. 2. SPb: Polytechnic University Publishing House, 2016. pp. 462-473.

5. Котов С. С. Автоматизация процесса проектирования учебных планов образовательных программ нового поколения / С. С. Котов // Материалы Всероссийской научно-практической конференции с международ- 
ным участием «Информационные технологии в обеспечении нового качества высшего образования». М.: Изд-во МИСиС. 2010. Т. 2. С. 284-289.

6. Кривицкая М. А. Методы и алгоритмы проектирования рабочих учебных планов в условиях новых образовательных стандартов / М. А. Кривицкая. Автореферат диссертации на соискание ученой степени кандидата технических наук. ГБОУ ВПО «Сургутский государственный университет ХМАО-Югры». 2015. 22 с.

7. Орлова О. Н. Разработка моделей и автоматизированных процедур для исследования взаимосвязи дисциплин в учебном плане / О. Н. Орлова // Научно-технические ведомости СПбГТУ. 2002. № 4. С. 93-102.

8. Найханова Л. В. Методы и алгоритмы принятия решений в управлении учебным процессом в условиях неопределенности: монография / Л. В. Найханова, С. В. Дамбаева. Улан-Удэ: Изд-во ВСГТУ, 2004. 164 с.

9. Орлова О. Н. Методика анализа взаимодействия между дисциплинами в учебном плане / О. Н. Орлова // В сб.: Матер. межвуз. научн. конф. XXIX недели науки СПб ГТУ (факультет экономики и менеджмента, междунар. Высшая школа управления). СПб.: СПбГТУ, 2001. С. 77-78.

10. H. Liu. Learning concept graphs from online educational data / H. Liu, W. Ma, Y. Yang, J. Carbonell // Journal of Artificial Intelligence Research (JAIR). 2016. № 55. 1059-1090.

11. Y. Yang. Concept graph learning from educational data / Y. Yang, H. Liu, J. Carbonell, W. Ma // Proceedings of the Eighth ACM International Conference on Web Search and Data Mining. 2015. pp. 159-168. URL: http://doi.org/ 10.1145/2684822.2685292.

12. Фридман О. В. Анализ программных продуктов для автоматизации формирования учебного плана вуза / О. В. Фридман // Труды Кольского научного центра РАН. 2015. № 3(29). URL: https://cyberleninka.ru/article/n/ analiz-programmnyh-produktov-dlya-avtomatizatsii-formirovaniya-uchebnogo-plana-vuza.

13. Lightfoot, Jay M. A Graph-Theoretic Approach to Improved Curriculum Structure and Assessment Placement / Jay M. Lightfoot. 2010.

14. S. Pasterk. Graph-based analysis of computer science curricula for primary education / Stefan Pasterk, Andreas Bollin. Published in IEEE Frontiers in Education Conference (FIE) 2017. DOI:10.1109/FIE.2017.8190610.

15. Pasterk S. A Graph-based Approach to Analyze and Compare Computer Science Curricula for Primary and Lower Secondary Education / Stefan Pasterk, Andreas Bollin. Published in ITiCSE 2017. DOI:10.1145/3059009.3072985.

\section{References}

1. Agadzhanov, G. G. \& Naydenko, V. S. \& Toiskin, V. S. Nekotorye kriterii optimizatsii uchebnykh planov. Retrieved from http://econf.rae.ru/article/7755 [in Russian].

2. Volkova, V. N. \& Efremov, A. A. \& Loginova, A. V. \& Kabinetskaya, D. A. \& Tambaum, M. A. (2016). Modeli i avtomatizirovannye tekhnologii dlya razrabotki uchebnykh planov. Journal of Otkrytoe obrazovanie, 6, 51-58 [in Russian].

3. Denisov, A. A. (2009). Sovremennye problemy sistemnogo analiza. SPb.: Izd-vo Politekhnicheskogo universiteta, 304 p. [in Russian]. 
4. Efremov, A. A. \& Kabinetskaya, D. A. \& Tambaum, M. A. (2016). System analysis of the development of workplans for the preparation of bachelors. Journal of System analysis in design and management: Collection of Scientific Works XVIII Int. scientific and practical conf., 2, 462-473 [in Russian].

5. Kotov, S. S. (2010). Avtomatizatsiya protsessa proektirovaniya uchebnykh planov obrazovatel'nykh programm novogo pokoleniya. Journal of Materialy Vserossiyskoy nauchno-prakticheskoy konferentsii s mezhdunarodnym uchastiem 'Informatsionnye tekhnologii v obespechenii novogo kachestva vysshego obrazovaniya', Vol. 2, 284-289 [in Russian].

6. Krivitskaya, M. A. (2015). Metody i algoritmy proektirovaniya rabochikh uchebnykh planov $v$ usloviyakh novykh obrazovatelenykh standartov, $22 \mathrm{p}$. [in Russian].

7. Orlova, O. N. (2002). Razrabotka modeley i avtomatizirovannykh protsedur dlya issledovaniya vzaimosvyazi distsiplin $v$ uchebnom plane. Journal of Nauchno-tekhnicheskie vedomosti SPbGTU, 4, 93-102 [in Russian].

8. Naykhanova, L. V. \& Dambaeva, S. V. (2004). Metody i algoritmy prinyatiya resheniy $v$ upravlenii uchebnym protsessom $v$ usloviyakh neopredelennosti. Ulan-Ude: Izd-vo VSGTU, 164 p. [in Russian].

9. Orlova, O. N. (2001). Metodika analiza vzaimodeystviya mezhdu distsiplinami v uchebnom plane. Journal of Mater. mezhvuz. nauchn. konf. XXIX nedeli nauki SPb GTU (fakul'tet ekonomiki i menedzhmenta, mezhdunar. Vysshaya shkola upravleniya). SPb.: SPbGTU, 77-78 [in Russian].

10. Liu, H. \& Ma, W. \& Yang, Y. \& Carbonell, J. (2016). Learning concept graphs from online educational data. Journal of Artificial Intelligence Research (JAIR), 55, 1059-1090 [in English].

11. Yang, Y. \& Liu, H. \& Carbonell, J. \& Ma, W. (2015). Concept graph learning from educational data. Journal of Proceedings of the Eighth ACM International Conference on Web Search and Data Mining, 159-168. Retrieved from http://doi.org/10.1145/2684822.2685292 [in English].

12. Fridman, O. V. (2015). Analiz programmnykh produktov dlya avtomatizatsii formirovaniya uchebnogo plana vuza. Journal of Trudy Kol'skogo nauchnogo tsentra RAN, 3(29). Retrieved from https://cyberleninka.ru/article/n/analizprogrammnyh-produktov-dlya-avtomatizatsii-formirovaniya-uchebnogo-planavuza [in Russian].

13. Lightfoot, Jay M. (2010). A Graph-Theoretic Approach to Improved Curriculum Structure and Assessment Placement [in English].

14. Pasterk, S. \& Bollin, A.(2017). Graph-based analysis of computer science curricula for primary education. Journal of Published in IEEE Frontiers in Education Conference (FIE). DOI:10.1109/FIE.2017.8190610 [in English].

15. Pasterk, S. \& Bollin, A. (2017). A Graph-based Approach to Analyze and Compare Computer Science Curricula for Primary and Lower Secondary Education. Journal of Published in ITICSE. DOI:10.1145/3059009.3072985 [in English].

\section{В статье на основании анализа работ в области составления учебных планов предлагается применение методики изу- чения корреляционных процессов в структуре обучения средствами теории графов. Исследование базируется на предположении о корреляции относительного объема}


преподавания дисциплины в учебном плане и ее востребованности в формировании профессиональных компетенций выпускника. Внедрение результатов исследования позволит увеличить объективность средств математического моделирования и информационной поддержки в задачах оптимизации учебных планов, распределения циклов дисциплин учебных планов по семестрам обучения.

Ключевые слова: Учебный план; теория графов; структура обучения; дисциплина; кредит; компетенция; информационные технологии.

In the article on the basis of an analysis of works in the drafting of the syllabus, offered to use the methods of correlation processes study in the structure of learning by means of the theory of graphs. Quality of specialists preparation is determined by educational standards on the basis of which higher educational institution develops the curricula of specialties and specializations. Research results will allow increasing of the facilities objectivity of mathematical design and informative support in the tasks of optimization of curricula, distribution of cycles of disciplines of curricula on the semesters of studies.

Keywords: Curriculum; graph theory; learning structure; discipline; credit; competence; information technology. 